\title{
Bases for a Methodology Assessing Time Complementarity in Space
}

\author{
Alfonso Risso, Alexandre Beluco \\ Universidade Federal do Rio Grande do Sul, Porto Alegre, Brazil \\ Email: albeluco@iph.ufrgs.br
}

How to cite this paper: Risso, A. and Beluco, A. (2017) Bases for a Methodology Assessing Time Complementarity in Space. Energy and Power Engineering, 9, 527-540. https://doi.org/10.4236/epe.2017.99037

Received: January 25, 2017

Accepted: August 28, 2017

Published: August 31, 2017

Copyright $\odot 2017$ by authors and Scientific Research Publishing Inc. This work is licensed under the Creative Commons Attribution International License (CC BY 4.0).

http://creativecommons.org/licenses/by/4.0/

\begin{abstract}
Energetic complementarity has been studied in recent years and can be an important tool for managers to decide on the design and operation of hybrid systems based on renewable energy resources. Complementarity is an ability presented by two or more energy resources to complement each other over time. Complementarity can be verified in one place or at different places. This second case can be termed as spatial complementarity and is more complex than the complementarity in the same place, requiring a specific approach for its quantification This paper discusses concepts related to energetic complementarity and presents the basis for a method to evaluate energetic timecomplementarity across space, applying the concepts presented to the northern coast of the state of Rio Grande do Sul, the southernmost state of Brazil.
\end{abstract}

\section{Keywords}

Energetic Complementarity, Energetic Complementarity in Time, Energetic Complementarity in Space, Hydro Energy, Wind Power

\section{Introduction}

Energetic complementarity, as considered in this work, is a capacity presented by two energy resources to complement each other (completely or partially) in time and-or space. Beluco et al. [1] [2] proposed a dimensionless index that allows quantifying the temporal complementarity, dividing it into three components: time, energy and amplitude. This paper deals only with the application of the first of these three components.

This concept was designed to initially assess energetic complementarity in one place. However, complementarity can be verified between power plants located in the same location (or near each other), but also between power plants located far from each other. This second case extends the applicability of the concept of 
energetic complementarity and requires a method to express this spatial complementarity with maps.

This paper presents the basis for a method that allows quantifying complementarity throughout space and presents its application to a region in the State of Rio Grande do Sul. This paper also discusses some limitations of this method and next steps to be followed to improve the understanding of spatial complementarity. This paper clearly establishes basic concepts for the future layout of spatial complementarity maps.

\section{Complementarity in Time across Space}

Beluco et al. [1] [2] proposed a dimensionless index evaluating complementarity between two energy resources and defined its three components. The timecomplementary index was defined as shown in Equation (1), where $\kappa_{t}$ is the partial energetic complementarity in time, where maximum and minimum availability of hydraulic energy occur, respectively, on Julian day number $D_{h}$ and $d_{h}$ (likewise $D_{s}$ and $d_{s}$ refer to the same days regarding solar energy). Note that if the differences $|\mathrm{D}-\mathrm{d}|$ equal 180 , then $\kappa_{\mathrm{t}}=\left|\mathrm{d}_{\mathrm{h}}-\mathrm{d}_{\mathrm{s}}\right| / 180$, so that $\kappa_{\mathrm{t}}=1$ if the maxima are 180 days apart, and $\kappa_{\mathrm{t}}=0$ if the maxima coincide.

$$
\kappa_{\mathrm{t}}=\frac{\left|\mathrm{d}_{\mathrm{h}}-\mathrm{d}_{\mathrm{s}}\right|}{\sqrt{\left|\mathrm{D}_{\mathrm{h}}-\mathrm{d}_{\mathrm{h}}\right|\left|\mathrm{D}_{\mathrm{s}}-\mathrm{d}_{\mathrm{s}}\right|}}
$$

On this work, spatial complementarity will be evaluated from the calculation of this temporal index, with the difference that the index will be calculated with resource data at different locations and no longer with data from two sources in the same place, as estimated by Beluco et al. [1].

So, for clarity of concepts, in this paper the complementarity calculated in only one place applying the index proposed by ref. [1] will be referred to as temporal complementarity. In turn, the complementarity calculated even by the index proposed by ref. [1] but considering two different locations in space will be termed as spatial complementarity.

\section{A Graphical Method Assessing Complementarity in Space}

This section will initially present a graphical method for evaluating spatial complementarity and will then describe some examples designed to demonstrate its applicability.

The proposed method for evaluating spatial complementarity in a given region consists of the following four steps: [1] establish a network of hexagonal cells over the region to be studied; [2] calculate the complementarity in time, applying Equation (1) above, among all the cells of that network; [3] compare the obtained results in order to associate for each distance the maximum value obtained for the complementarity in time; [4] plot the results of maximum complementarity in time as a function of the distance between the cells.

The study of spatial complementarity requires the establishment of a region to 
be studied and its modeling with a network of cells. In this paper, a network of hexagonal cells will be adopted, as they allow a better coverage of the surface. Each cell in this network will be assigned power generation information resulting from the added effect of all power plants in its area of influence. This step will be better understood in the next section, when a real case is analyzed.

The size and arrangement of the cells can be established according to the nature of the available energy resources or characteristics of the region to be studied. Once the data associated with the generating units of the study region are known, temporal complementarity can be determined with the application of Equation (1).

Just for simplicity, the examples described in this section throughout the next figures will consider the case where the differences shown below in Equation (1) are equal to 6 . Thus, the months corresponding to the availability minima can be directly applied to upper part of this equation, leading to the evaluation of complementarity in time.

Figure 1 shows a hexagonal cell network used for determination of spatial complementarity. This network can have the dimensions of its cells adapted to the conditions of the region under study or to the number of plants operating in that region.It is appropriate to set up one network for each type of energy resource used.

In this network, there are plants only in the central cell, which appears marked with a specific color, and there are indications of the months of the year in which maximum and minimum energy availability occurs. In the case of only one plant, the corresponding months of the energy resources available for this

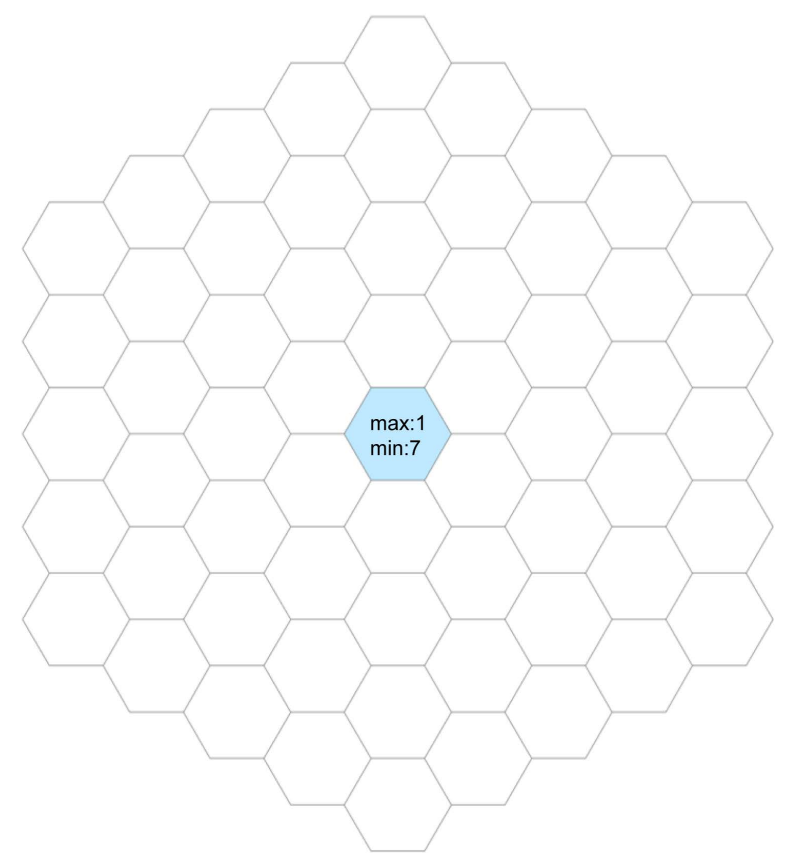

Figure 1. A net with hexagonal cells containing power plants in the center position. 
plant will be indicated. In case this cell contains more than one plant, the months of maximum and minimum energy availability corresponding to the joint effect of the plants of that cell should be indicated.

Figure 2 shows two networks side by side, showing hypothetical generation information for two energy resources. The network on the left shows information for hydroelectric power and the grid on the right for wind energy. The network on the left indicates hydroelectric plants only in the central cell, while the network on the right affects plants in the two cross-hatched cells. So only three cells in this region include power plants. The network shown on the left is identical to the network shown in Figure 1.

A trivial situation, considering the determination of complementarity index, would be obtained by comparing two such networks, mounted to a region in which the compared plants were both located in the central cell. It would be equivalent to the calculation already known for the temporal complementarity in just one place. Results for such a case can lead to complementarity maps such as those presented by Beluco et al. [1] for the State of Rio Grande do Sul.

The central cell of the left network indicates that the maximum availability occurs in January (month 1, from 1 to 12) while the minimum in the month of July (month 7). The cells on the right network indicate that maximum availability occurs in July while the minimum occurs in January. As the months of minimum availability of hydropower and wind energy are in this case with a difference of six months, these two energy resources present a complete complementarity and the index results equal to 1 .

This result should be presented as a function of distance and a very appropri-
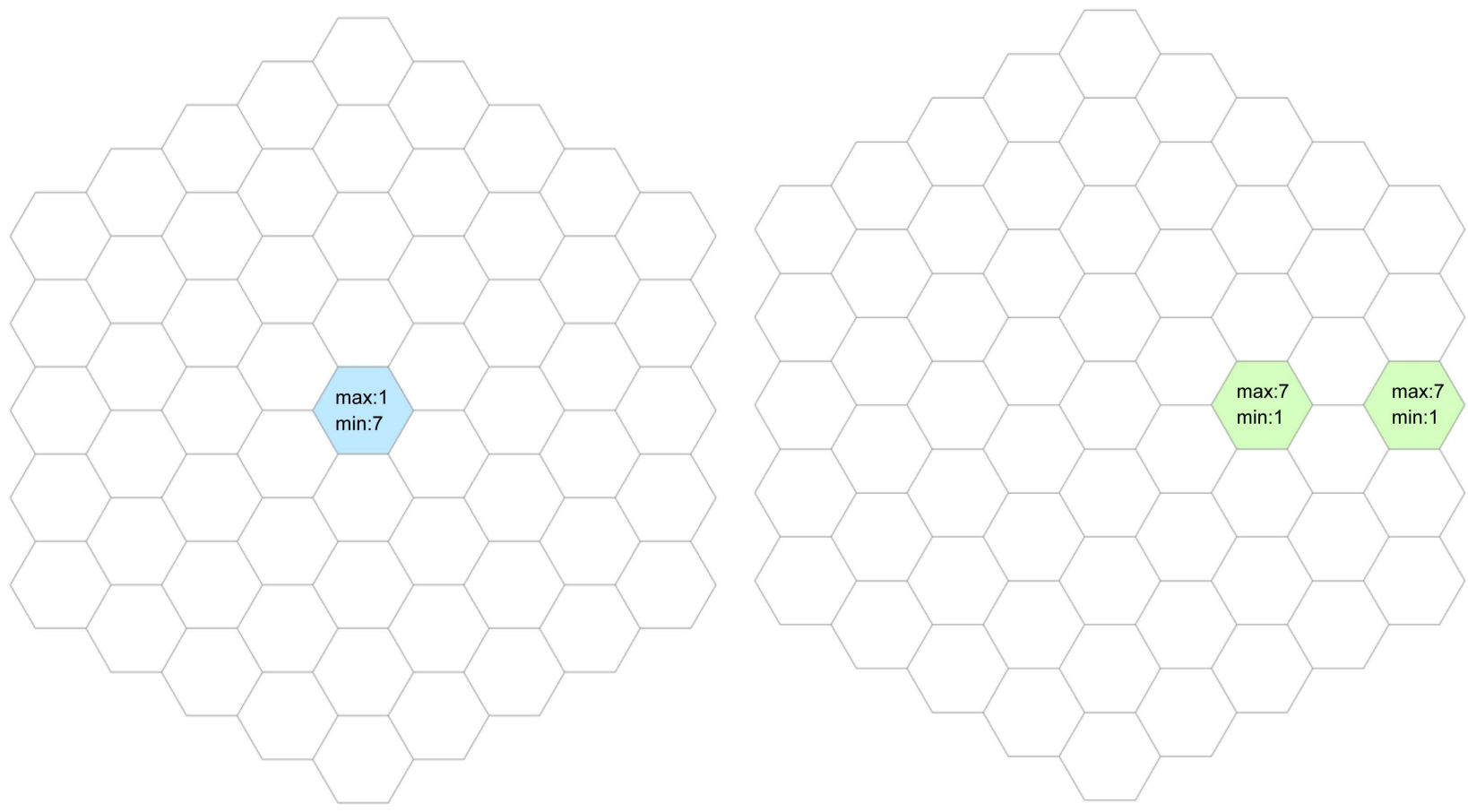

Figure 2. Nets with hexagonal cells indicating hydroelectric plants (left) and wind plants (right) in the region under consideration. 
ate form for this presentation is shown in Figure 3. There is perfect complementarity between the central cell in the network shown on the left and each of the two cells shown in the network on the right. The distances between the central cell and the other two cells can be considered to be 2 and 4, respectively. Thus, a bar with height 1 appears in abscissa or distance equal to 2 and another also with height 1 appears atdistance 4 .

If there were power plants in matching cells, complementarity between these cells could be considered to compose maps of complementarity, as discussed above. As power plants do not appear in matched cells in Figure 2, the complementarity indicated in abscissa 0 in Figure 3 equals zero. However, information at other distances could be used to compose complementarity maps corresponding to certain distances between cells or corresponding to intervals of distances between cells.

In the sequence, some other basic cases, for a better understanding, will be presented and discussed. Figure 4 shows a case in which a hydroelectric plant is inserted in a region with wind turbines in all cells of the network, presenting energy availabilities with the same distributions of Figure 2. Figure 5 shows the spatial complementarity for this case, of course with unit values for all distances between cells. If there were different values of complementarity, the maximum values would be shown in the graph.

The situation in Figure 2 sets up a complementarity in time that is total for two of the available distances, while the situation in Figure 4 configures a complementarity that is complete at all distances available in the network of hexagonal cells under analysis. The total complementarity, considering its three components, as presented and discussed by Beluco et al. [1], should also take into account the components of energy and amplitude.

Figure 6 shows a situation where a hydroelectric plant (left) placed in the central cell has its complementarity established with a distribution (right) of

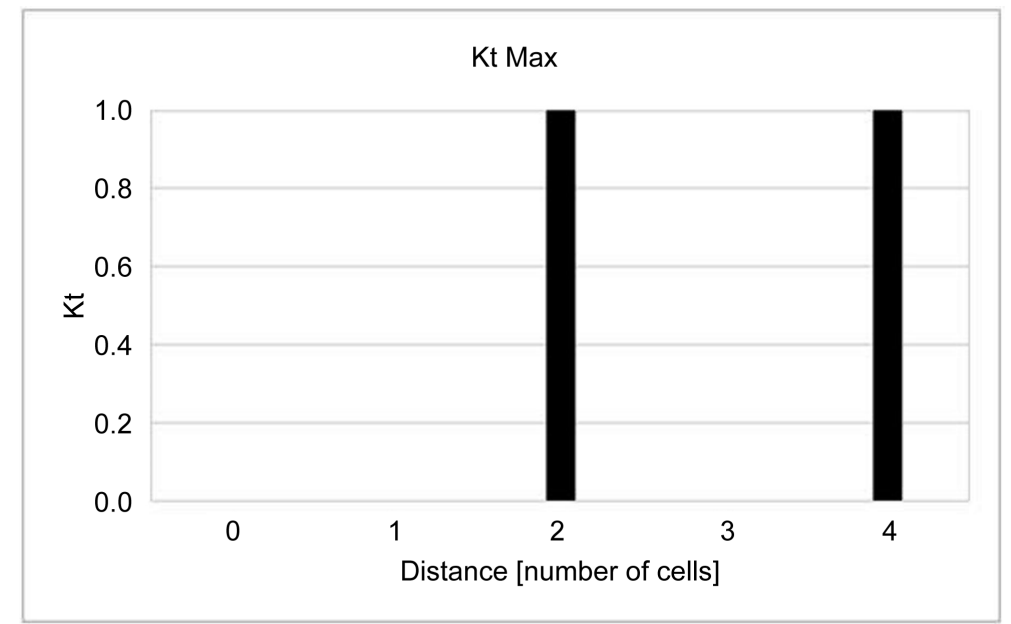

Figure 3. Spatial complementarity for the hypothetic region with power plants indicated in Figure 2, with temporal complementarity indicated as a funciont of distance. 

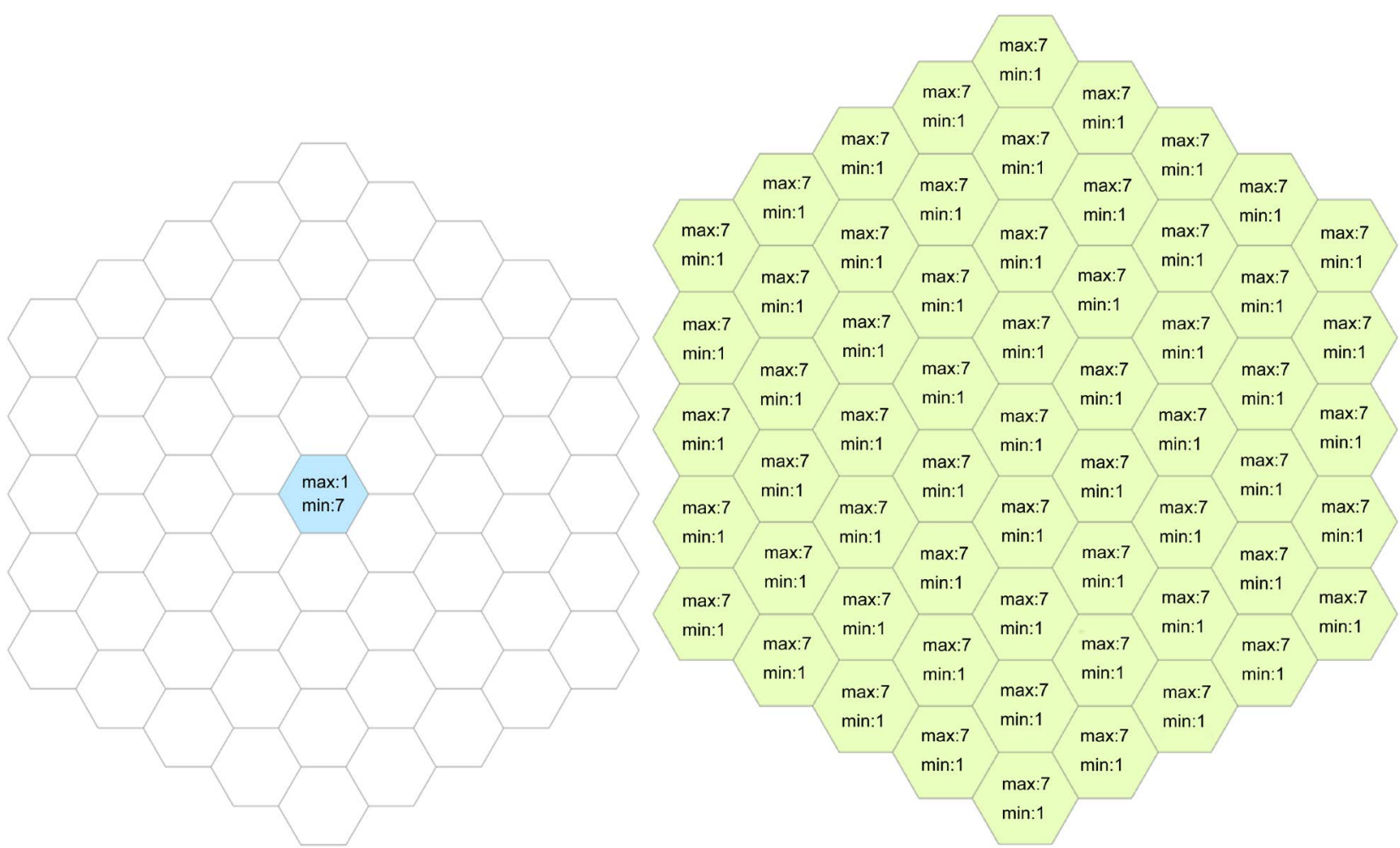

Figure 4. Nets corresponding to a region with one hydroelectric power plant (left) inserted in a region fiull of wind turbines (right).

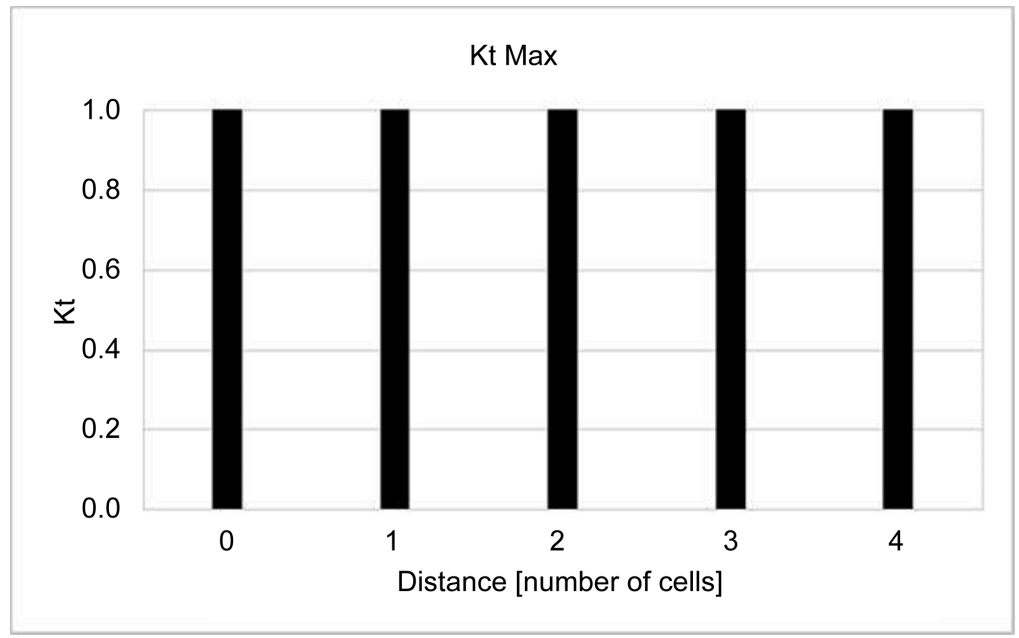

Figure 5. Spatial complementarity for the case of Figure 4.

wind turbines in which there is a set of turbines in the central cell and other sets distributed in cells in the periphery of the analyzed region. These cells have the same maximum and minimum energy availability distributions of the previous cases. The comparisons will become more complex as there are more cells in the network on the left, as already appears in the next case.

Figure 7 shows the spatial complementarity for the case of Figure 6. The first bar corresponds to the comparison of the central cells and corresponds also to 

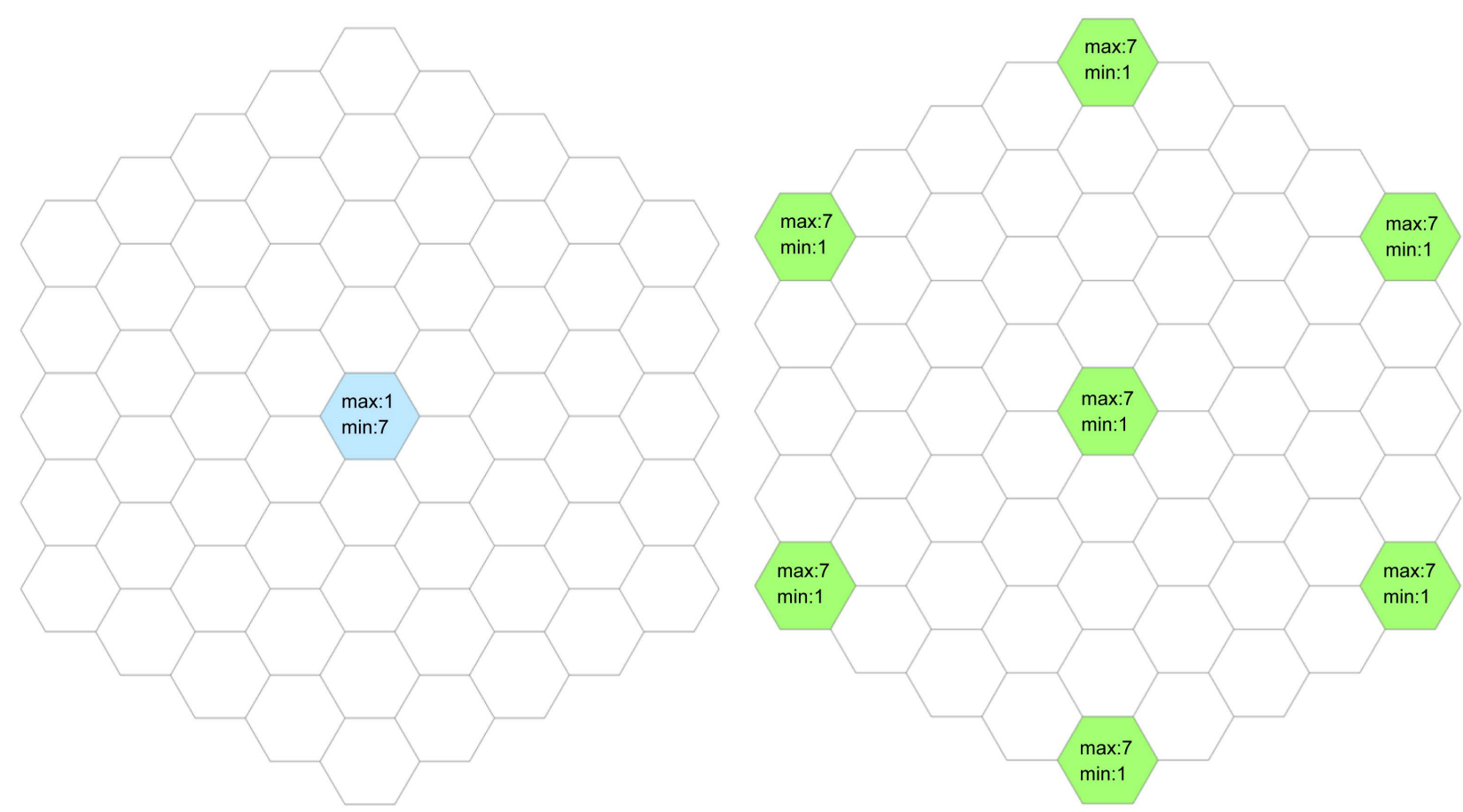

Figure 6. Nets corresponding to a region with one hydroelectric power plant (left) inserted in a region with wind turbines (right) in the center and in some cells of the extremity of the region.

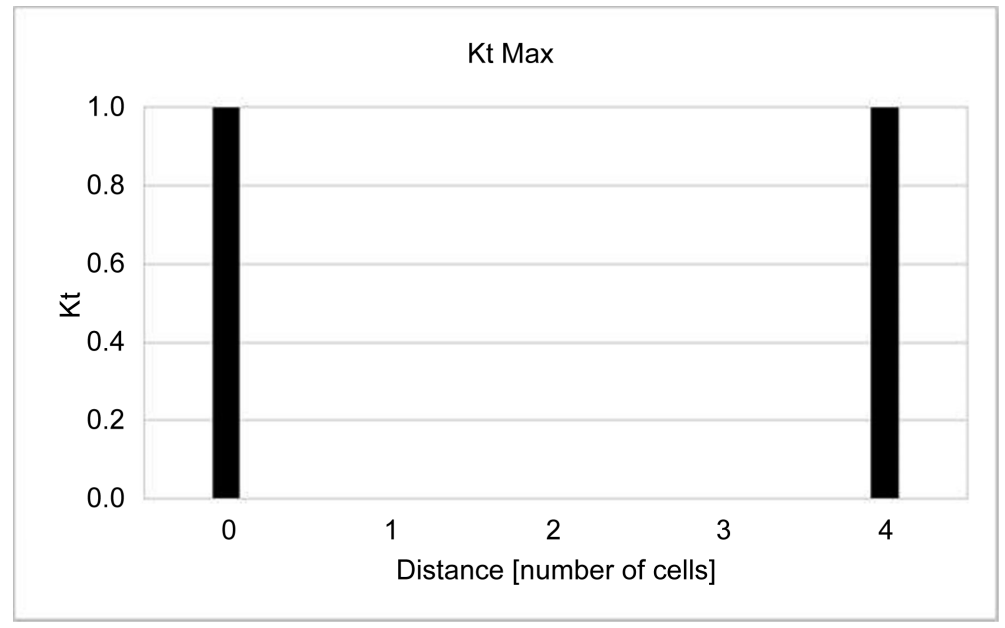

Figure 7. Spatial complementarity for the case of Figure 6.

the trivial case discussed above. The other bar corresponds to the comparison of the central cell of the network on the left with the cells on the periphery of the network on the right. As the lags correspond in these cases to six months, the values of complementarity correspond to the complete complementarity.

The cases above, shown in Figure 2, Figure 4 and Figure 6, can be considered simple because the networks on the left always have only one cell with hydroelectric plants. The cases in which the left network presents more than one cell with hydroelectric plants can be solved in the same way, establishing values of temporal complementarity from the comparison of cells in the left and right 
networks.

Figure 8 shows a distribution of power plants in the networks closest to reality. In the left network there are two cells with hydroelectric plants, while the network on the right presents four cells containing wind turbines. On the right, the cell in darker green is differentiated from the others because it presents a distribution of maximum and minimum energy availability different from those that were being adopted in the previous cases.

Figure 9 shows the graph with spatial complementarity as a function of distance for the case of Figure 8. At distances in which complementarities are partial, if they correspond to more than one value of complementarity for the same distance, the larger result is shown in the diagram. It is for the distance $d$ equal to 3 that appears in the diagram a value of complementarity smaller than the unit.

Figure 10 shows a more complex situation than the previous ones, in which several cells containing plants in the two networks appear. In addition, these plants exploit energy resources with maximum and minimum energy availability in different months throughout the year. In the left network, the cells in dark blue, and in the network of the right the cells in dark green, present distributions of energy availability different from the distributions of the previous cases.

Figure 11 shows the spatial complementarity diagram corresponding to this case. This diagram does not show all the distances between cells containing power plants, and furthermore shows many unitary results, which present a kind of "saturation" over possible complementarity results. This is clearly a limitation
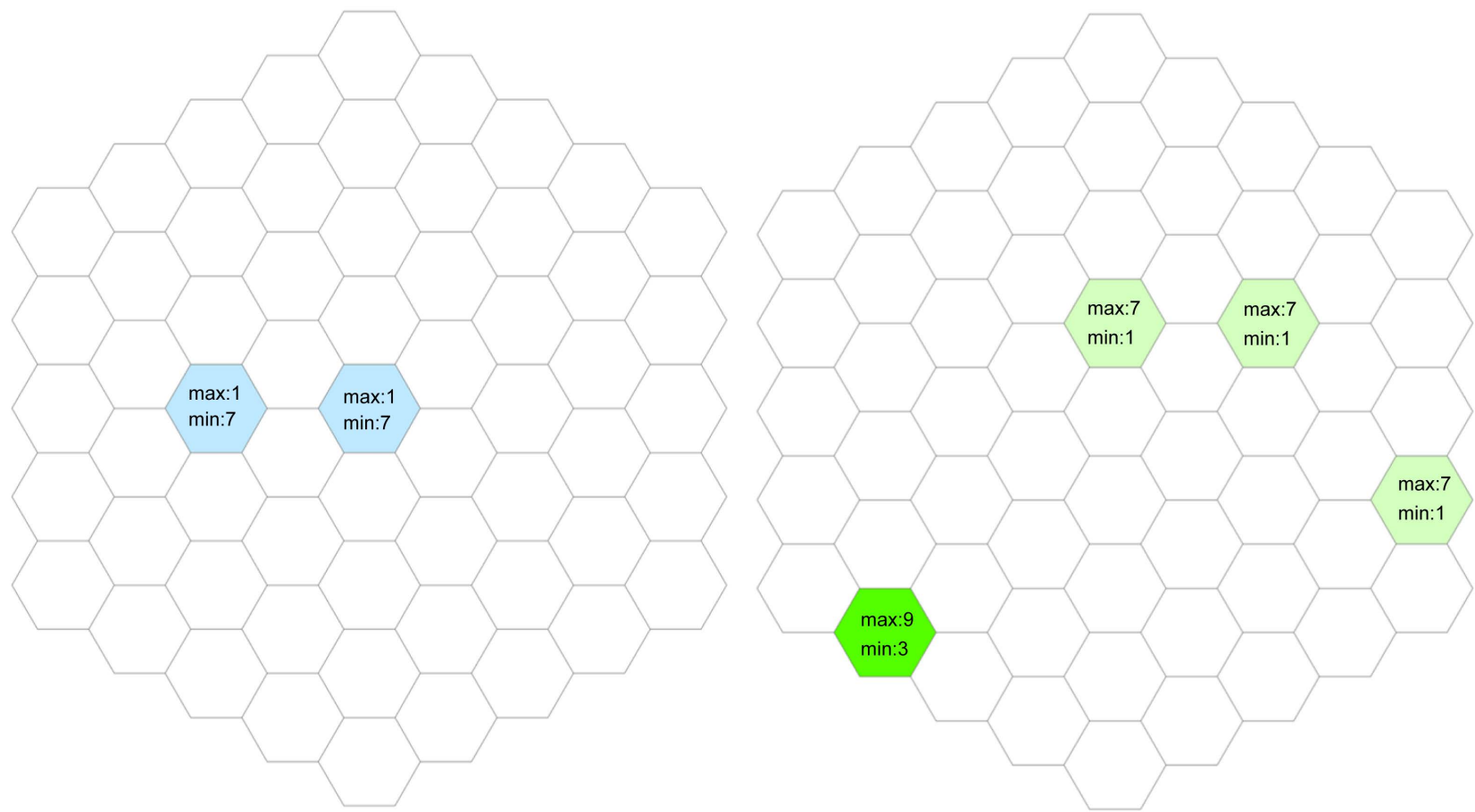

Figure 8. Nets corresponding to a region with two cells containing hydro power plants (left) and four cells containing wind turbines (right). 


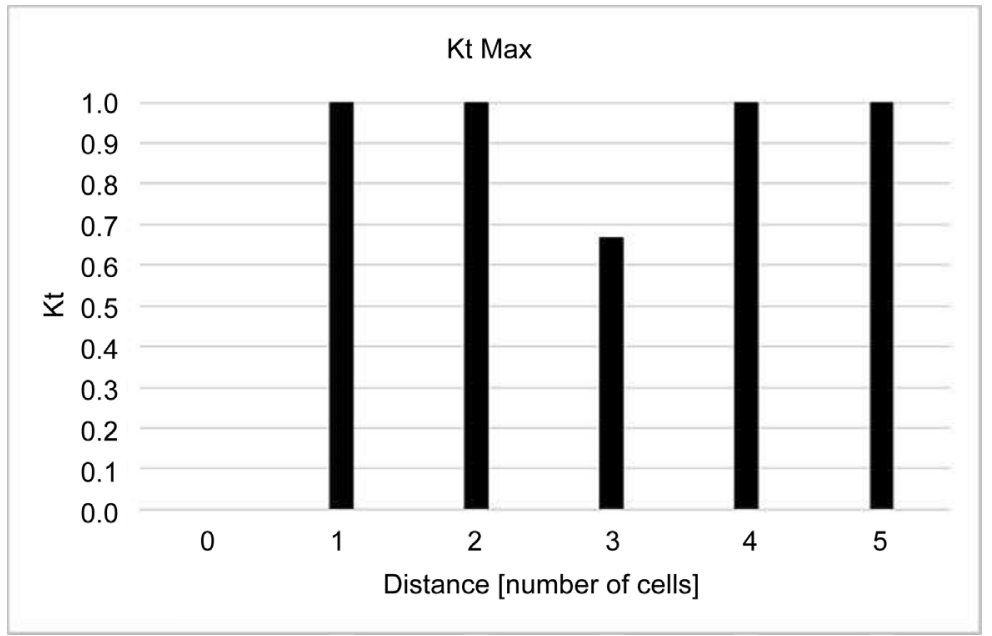

Figure 9. Spatial complementarity for the case of Figure 8.
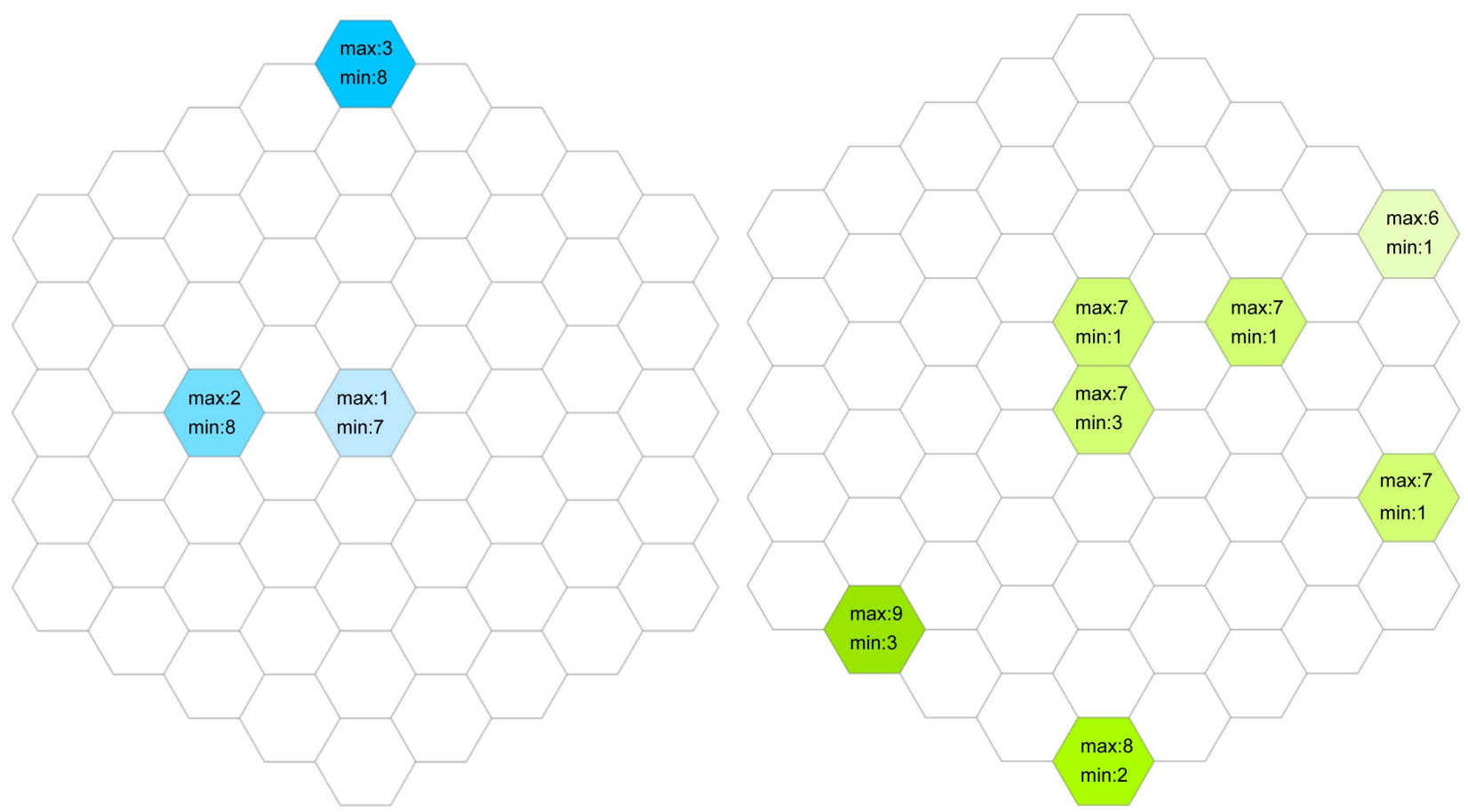

Figure 10. Nets corresponding to a region with threecells containing hydro power plants (left) and seven cells containing wind turbines (right).

of the presented method, and may be circumvented possibly with complementarity digrams that do not show only the maximum values at each distence.

This process for evaluating the spatial complementarity allows assessment of how power plants located in a given region may present complementary. Before this paper, this would be possible only peer-to-peer and now an evaluation is possible comparing plants at different sites. The survey of full complementarity can be an important tool for planning and management of energy resources.

One limitation is that spatial complementarities across different distances are represented in the same diagram. Another limitation is that different comple- 


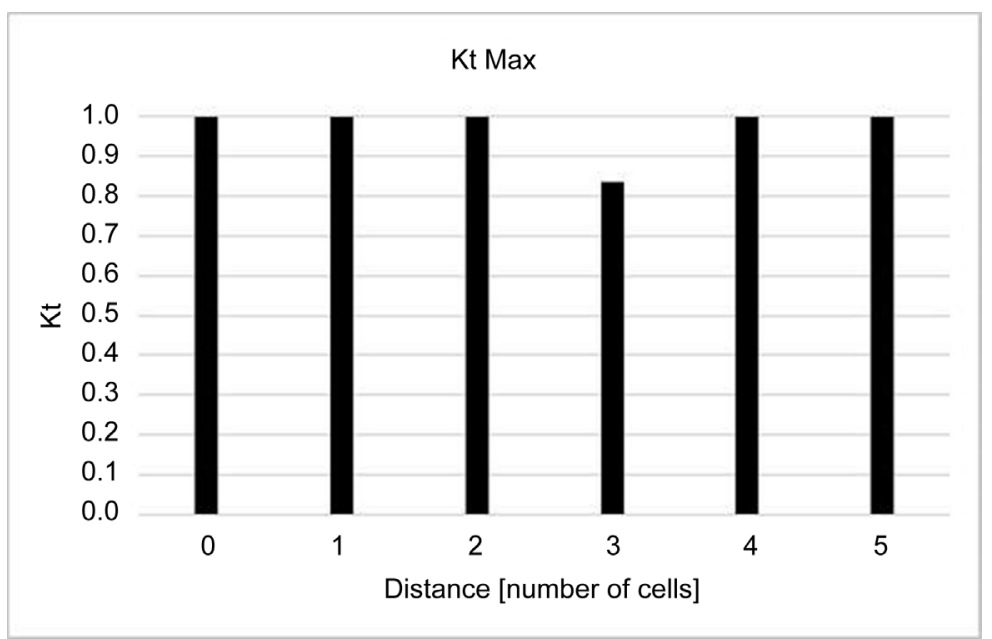

Figure 11. Spatial complementarity for the case of Figure 10.

mentarities in the same distance will be shaded by the criterion adopted to define what complementarity will be in this position. In this paper, the graphs were assembled considering the maximum values in each distance, but average values of complementarity could also be adopted.

\section{An Example of Application}

The region of the north coast of the state of Rio Grande do Sul, in the extreme south of Brazil, will be used for an example of application. This region can be viewed on Google Maps [3] and is shown in Figure 12. A 500 square kilometer cell network was set up to allow this assessment. The figure shows this network and shows that there are hydroelectric plants in two cells and that there are wind turbines in three cells.

Figure 13 shows the complementarity diagram for the region shown in Figure 12. The maximum and minimum energy availability distributions for hydroelectric plants and wind turbines in this case have complete complementarity and this is expressed in the diagram. The data for this analysis were obtained with the HidroWeb [4] system, available online, and the Wind Atlas [5] of the State of Rio Grande do Sul, having been manipulated as proposed by Beluco et al [1].

Figure 14 and Figure 15 respectively show the locations of hydro power plants and wind farms identified in the region shown in Figure 12. Figure 14 identifies the five hydroelectric power plants with numbers from 1 to 5 . In 1 the Herval [6] power plant is located, 2 is the Bugres [7] plant, 3 the Canastra [8] power plant, 4 the Toca [9] plant and in 5 is located the Passo do Inferno [10] power plant.

Figure 15 identifies the four wind farms with numbers from 1 to 14 . In 1 and 8 are located respectively Sangradouro II [11] and Sangradouro I [18] and Sangradouro III [24]; in 2, 6 and 11 are located respectively Lagoa dos Barros III [12], Lagoa dos Barros I [16] and Lagoa dos Barros II [21]; in 3, 9 and 12 are 


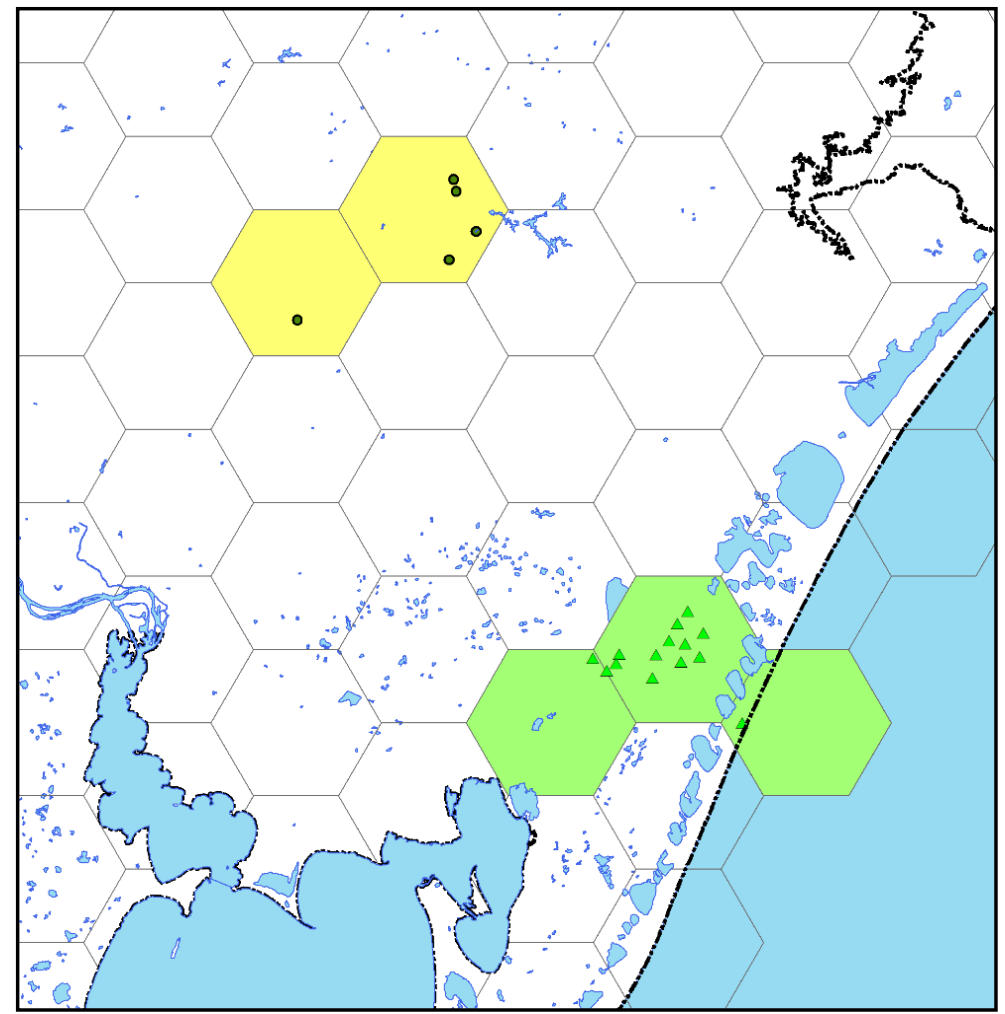

Figure 12. A network with $500 \mathrm{~km}^{2}$ cells assembled to evaluate spatial complementarity in the region of the northern coast of the State of Rio Grande do Sul.

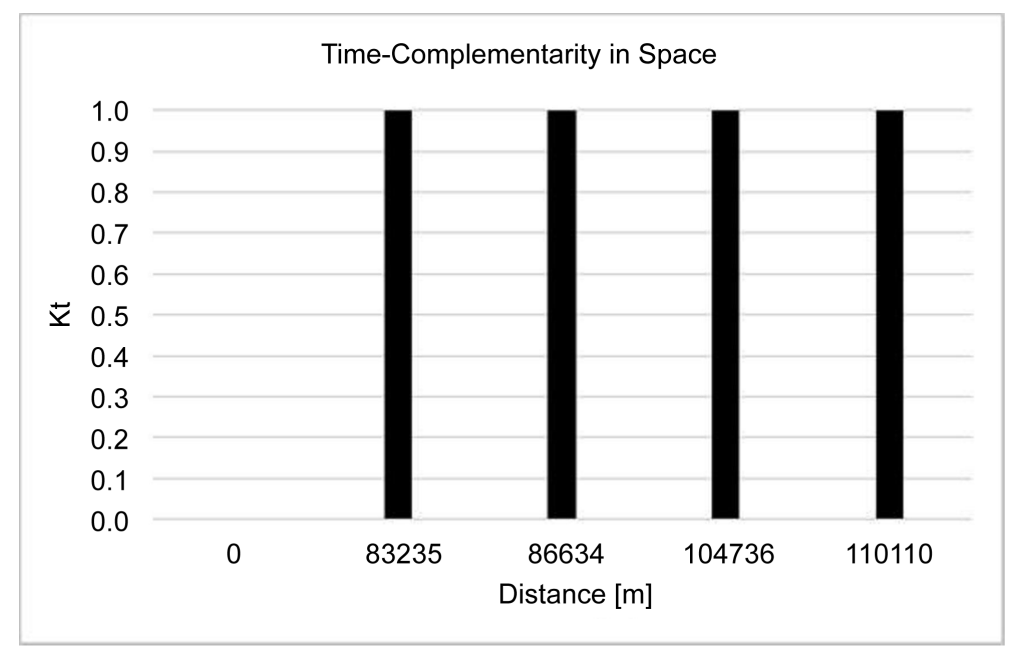

Figure 13. Spatial complementarity for the case of Figure 12.

located respectively Osório I [13], Osório II [19] and Osório III [22]; in 4, 10 and 13 are located respectively Índios III [14], Índios I [20] and Índios II [23]; in 5 is located the Chicolomã [15] wind farm and in 7 is located the Cidreira [17] wind farm.

The analysis undertaken in this paper considers only the months in which the minimum energy availability occurs in the power plants located in these two 


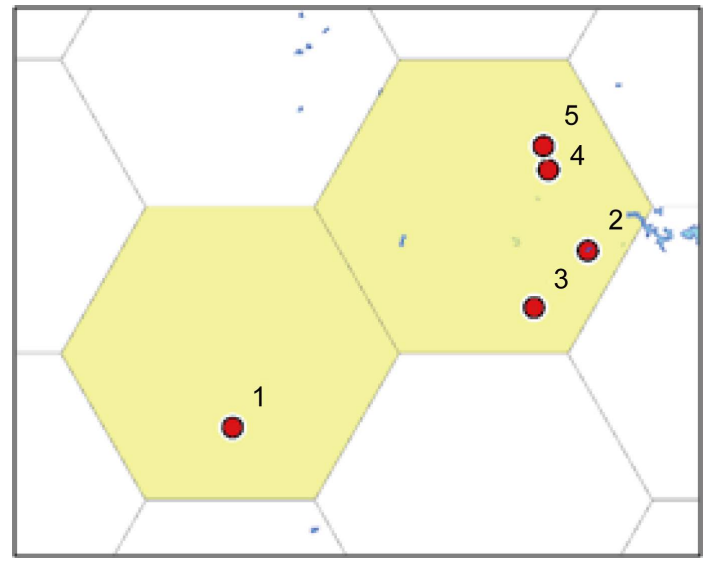

Figure 14. Location of the five hydroelectric power plants identified in two cells of the network shown in Figure 12 and considered for determining complementarity in Figure 13.

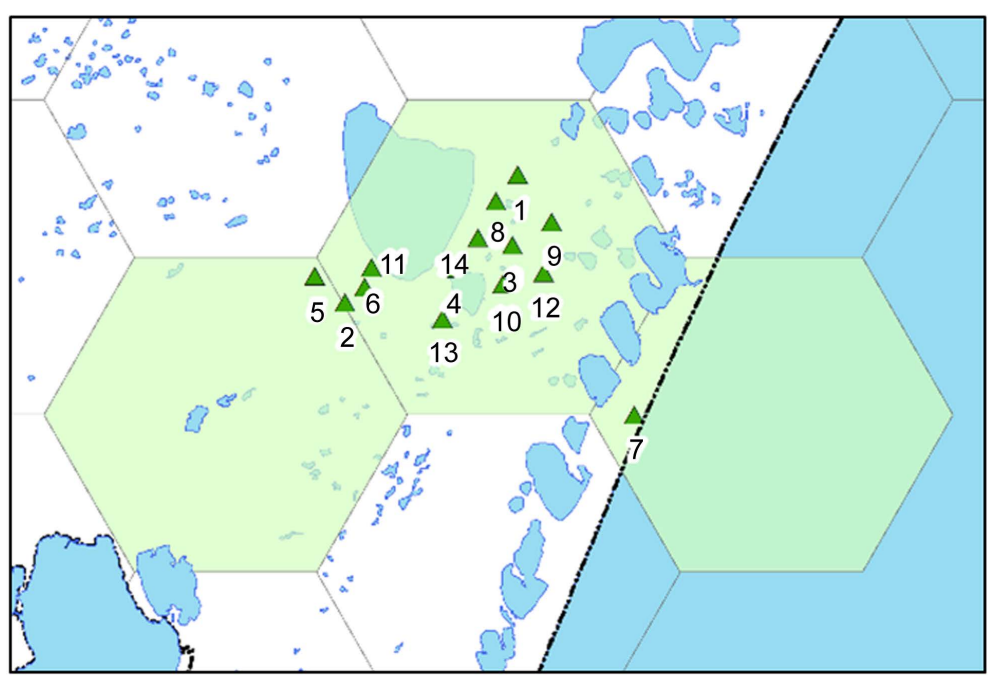

Figure 15. Location of the fourteen wind power plants identified in three cells of the network shown in Figure 12 and considered for determining complementarity in Figure 13.

figures; analyzes considering energy and amplitude complementarity components will be undertaken following the research work. It is necessary to express in the two dimensions of a map a much larger amount of information and this paper constitutes a first step in the description of spatial complementarity.

Some cells appear in these figures containing several plants, while others contain few or no plants at all. A prior evaluation of the complementarity components will enable assessing whether the hexagonal cell network has been well established. The purpose of the analysis to be undertaken may induce the choice of a network with smaller cells. The dimensions of the cell network to be adopted should be related to the expected results.

The establishment of the network cells may influence the results of the energetic complementarity assessment, if complementary plants appear in the same 
cell. This internal complementarity to a cell cannot be identified in the data collection that will result in the evaluation of complementarity. An analysis considering the largest power plants should be undertaken and of course the analysis of a region with many power plants may require large computational processing capacities.

\section{Final Remarks}

This paper discussed some issues related to energetic complemetarity and presented bases for a methodology allowing the determination of time complementarity through space. The proposal basically suggests the determination of the complementarity in time between different positions and their expression through a chart of complementarity as a function of distance. This paper also presented an application of the proposed methodology to the north coast of the State of Rio Grande do Sul, in southern Brazil.

The method has some limitations. One of them, spatial complementarity in several directions is presented in only one diagram, with superimposition of complementarity values for different directions in only one value. Another limitation, for a same distance, even in different positions, should be adopted only one value of complementarity; in principle, in this article, the maximum value was considered, but an average value could be considered.

\section{Acknowledgements}

This work was developed as a part of research activities on water resources management and renewable energy at the Instituto de Pesquisas Hidráulicas (IPH), Universidade Federal do Rio Grande do Sul (UFRGS). The authors acknowledge the support received by the institution. The second author acknowledges the financial support received from $\mathrm{CNPq}$ for his research work (proc. $\mathrm{n}$. 309021/2014-6.).

\section{References}

[1] Borba, E. and Brito, R. (2017) An Index Assessing the Energetic Complementarity in Time between More than Two Energy Resources. Energy and Power Engineering, 9, 505-514. https://doi.org/10.4236/epe.2017.99035

[2] Beluco, A., Souza, P.K., Livi, F.P. and Caux, J. (2015) Energetic Complementarity with Hydropower and the Possibility of Storage in Batteries and Water Reservoirs. In: Sørensen, B., Ed., Solar Energy Storage, Academic Press, London, 155-188. http://dx.doi.org/10.1016/B978-0-12-409540-3.00007-4

[3] https://goo.gl/maps/3ezz3m9fm2M2

[4] Water Resources National Agency (ANA); HidroWeb, Brazilian Water Resources Database. www.hidroweb.ana.gov.br

[5] Mines and Energy State Secretary, Rio Grande do Sul Wind Atlas. http://minasenergia.rs.gov.br/atlas-eolico-2016-03

[6] https://goo.gl/maps/PBxDo9kEcWB2

[7] https://goo.gl/maps/EDKWw5MWBqC2 
[8] https://goo.gl/maps/6cVRAGuTSaQ2

[9] https://goo.gl/maps/KMP31dzwJVR2

[10] https://goo.gl/maps/kyzFbHgbLK22

[11] Pianezzola, G., Krenzinger, A. and Canales, F. (2017) Complementarity Maps of Wind and Solar Energy Resources for Rio Grande do Sul, Brazil. Energy and Power Engineering, 9, 489-504. https://doi.org/10.4236/epe.2017.99034

[12] https://goo.gl/maps/Ex7F6y9gvPG2

[13] https://goo.gl/maps/m5ULeACSvDk

[14] https://goo.gl/maps/SL4pigs7bJC2

[15] https://goo.gl/maps/2hAFUGbdhEw

[16] https://goo.gl/maps/APib4Vvdcyu

[17] https://goo.gl/maps/df18LiQZL5F2

[18] https://goo.gl/maps/oM6iEMDhB6k

[19] https://goo.gl/maps/upE7VUgMkL92

[20] https://goo.gl/maps/jiGXfV1P4ez

[21] https://goo.gl/maps/eGhduuoqAXJ2

[22] https://goo.gl/maps/tLi8HmLnN9r

[23] https://goo.gl/maps/kdNYG9dtTNP2

[24] https://goo.gl/maps/xFjnUWVJBBx

\section{Scientific Research Publishing}

Submit or recommend next manuscript to SCIRP and we will provide best service for you:

Accepting pre-submission inquiries through Email, Facebook, LinkedIn, Twitter, etc. A wide selection of journals (inclusive of 9 subjects, more than 200 journals)

Providing 24-hour high-quality service

User-friendly online submission system

Fair and swift peer-review system

Efficient typesetting and proofreading procedure

Display of the result of downloads and visits, as well as the number of cited articles

Maximum dissemination of your research work

Submit your manuscript at: http://papersubmission.scirp.org/

Or contact epe@scirp.org 